\title{
Barriers Limiting Youth Access to Reproductive Health Services by Primary Health Care Facilities in Nigeria
}

\author{
Eremutha, Francis ${ }^{*}$, Veronica Chizoba Gabriel \\ Women Friendly Initiative (WFI), Federal Capital Territory (FCT), Nigeria
}

Copyright@2019 by authors, all rights reserved. Authors agree that this article remains permanently open access under the terms of the Creative Commons Attribution License 4.0 International License

\begin{abstract}
Youth represent a tremendously valuable asset to the society therefore working with them to make a healthy transition to adulthood is critical to the world's development now and in the future. The issue of youth-friendly health service has become a matter of concern as many young people still do not have access to such in the country. The community survey was designed to generate increased understanding of the barriers that limit youth access to sexual and reproductive health services(SRH) offered by Primary Health Care (PHC) facilities in Nigeria. Stratified and Purposive Sampling with qualitative and quantitative research methodology was adopted. Qualitative data were obtained through 12 Focus Group Discussions (FGDs) and 48 Key Informant Interviews (KIIs). For the quantitative component, an interviewer-administered questionnaire was used to elicit information from 300 randomly selected adolescents and youth. The mean age of respondents was $18.9 \pm 4.4$ years. Reported barriers to youth's access to SRH services were lack of awareness (67.3\%), cost of services (46.7\%), negative attitude of health care providers (39.7\%) and fear of parents and what people will say (32.0\%). The results shows that community mobilization for awareness creation and support on SRH issues (59.3\%), will support youth to better access SRH services in PHC facilities
\end{abstract}

Keywords Adolescents, Youth-friendly Health Services, Primary Health Care (PHC) Facilities

\section{Introduction}

Adolescents (10-19 years) and young people (10-35 years) represent a significant proportion (42.4\%) of Nigeria's population ${ }^{1}$. However, for many African youth, the transition through adolescence continues to be fraught with several challenges and difficulties. These include high rates of poverty, illiteracy, unemployment and underemployment, violence, sexual coercion and exploitation, substance abuse and other deviant social behaviours. Coupled with high rates of judgmental values by adults and negative societal/cultural attitudes which deny young people access to appropriate information and services especially on sexual and reproductive health, it is not surprising that African youth currently have some of the highest rates of HIV/AIDS in the world ${ }^{2}$. It is estimated that more than half of all new HIV infections are among young people, while between one quarter and one half of adolescent girls become mothers before they turn 18 . Adolescent girls are two to five times more likely to die during pregnancy or childbirth than women in their twenties ${ }^{3}$.

Today's generation of young people is the largest in history-nearly half of the world's population is under the age of 25. This large demographic of young people presents the world with an unprecedented opportunity to accelerate economic development and reduce poverty. However, young people, especially adolescent girls and young women, suffer disproportionately from negative sexual and reproductive health outcomes, which challenge their ability to contribute to their communities' and countries' development. Young people face substantial social and economic barriers in accessing sexual and reproductive health information and services, which is evidenced by persistently high levels of unmet need for contraception, maternal mortality, and HIV incidence. Young women aged 15 to 19 are twice as likely to die in childbirth as adult women, and half of all new HIV infections occur in young people between the ages of 15 and 24. Such negative sexual and reproductive health outcomes have economic, social, and health consequences that affect young people throughout their lives, as well as their families, countries, and the global community at large ${ }^{4}$.

The need for sexual and reproductive health services for 
young people has never been greater, for one thing, this is the largest-ever youth generation. Moreover, in many countries, young people are marrying later, and spending longer (often sexually active) intervals between puberty and marriage. In addition, the AIDS pandemic has heightened awareness on the need for information and services that can help young people protect themselves. Most countries now make some effort to provide sexual and reproductive health services for adolescents and young people. However the erroneous belief persists in many places that sexual and reproductive health services encourage sexual activity among adolescents. Ideally, sexual and reproductive health services for adolescents should be offered as a component of a broader cluster of support services. Many have established youth-friendly services designed specifically for young people. But most of these are on a small scale and many are run by NGOs. While NGOs can offer excellent and innovative services, they rarely have the resources to implement the programmes at the scale that is needed. Vast needs remain unmet. The availability of youth-friendly services has been shown to increase both the demand for and quality of adolescent health care ${ }^{5}$.

Youth-friendly sexual and reproductive health services are those that attract young people, respond to their needs, and retain young clients for continuing care. Youth-friendly services are based on a comprehensive understanding of what young people in a given society or community want, and on respect for the realities of their diverse sexual and reproductive lives. The aim is to provide all young people with services they trust and which they feel are intended for them ${ }^{6}$. All clients of sexual and reproductive health services have the right to information about the benefits and availability of services and to access these services, regardless of their race, gender, sexual orientation, marital status, age, religious or political beliefs, ethnicity or disability. They have a right to protect themselves from unwanted pregnancy, disease and violence and to decide freely whether and how to control their fertility and other aspects of their sexual health.

In many places, adequate services that cater to youth are not available. In other places, their utilization is extremely low. Young people are often discouraged from using such services because of cost, disapproval by providers and the community, logistical constraints (including inconvenient hours or lack of transportation), fears about violations of confidentiality, uncertainty, embarrassment, or simply because they are not aware of them. Stigma keeps many young people living with HIV from receiving the treatment they need. Another barrier is fact that services for young people may be piecemeal - focusing only on sexually transmitted infections, for example, or just on contraception. Or they may be offered in traditional adult' clinical settings where adolescents and young people may feel ill at ease. Sometimes providers themselves are not comfortable with the legal and moral responsibility of providing services to adolescents and youth ${ }^{7}$. Young people are often secretive especially when it comes to sexual and reproductive health, so they will need someone they can confide in ${ }^{8}$.

Lack of youth-friendly health services and the hostile attitude of healthcare providers are said to scare youth from accessing healthcare facilities. Due to the unfriendly attitude of healthcare providers, many youth now engage in all forms of unorthodox practices to solve their health needs. Most communities lack healthcare facilities and where such facilities exist, they are not well equipped. Some existing health facilities do not have qualified staff, thereby putting the lives of the people at risk. Apart from lack of the required facilities, health care service providers are also said to constitute barriers preventing young persons from accessing health facilities. Most of the care providers reportedly lack the knowledge and skills to address the healthcare needs of young persons. Primary Health Care facilities have great potential for scaling-up and sustaining youth-friendly SRH services, particularly because these facilities are the nearest facilities to communities, and have the support of the Nigerian government, the study therefore assessed the barriers limiting youth from accessing sexual and reproductive health services offered at the primary health care facilities in Nigeria.

\section{Methodology}

The study was conducted in Ondo State (South West), Edo State (South South) and FCT (North Nigeria). The findings from the three states were generalised for the entire country.

The study population consisted of youth (10-24 years), community leaders, religious leaders, teachers, and parents living within selected communities. Participants were selected using stratified and purposive sampling from the rural and urban areas of the selected states.

The information from the FGD and KII were transcribed and analyzed for themes and contents. Also, the questionnaires were coded for data entry. It was then entered and analysed using SPSS (Statistical Package for the Social Sciences) software, Version 15.0. The quantitative data were analysed for frequency of occurrence. 


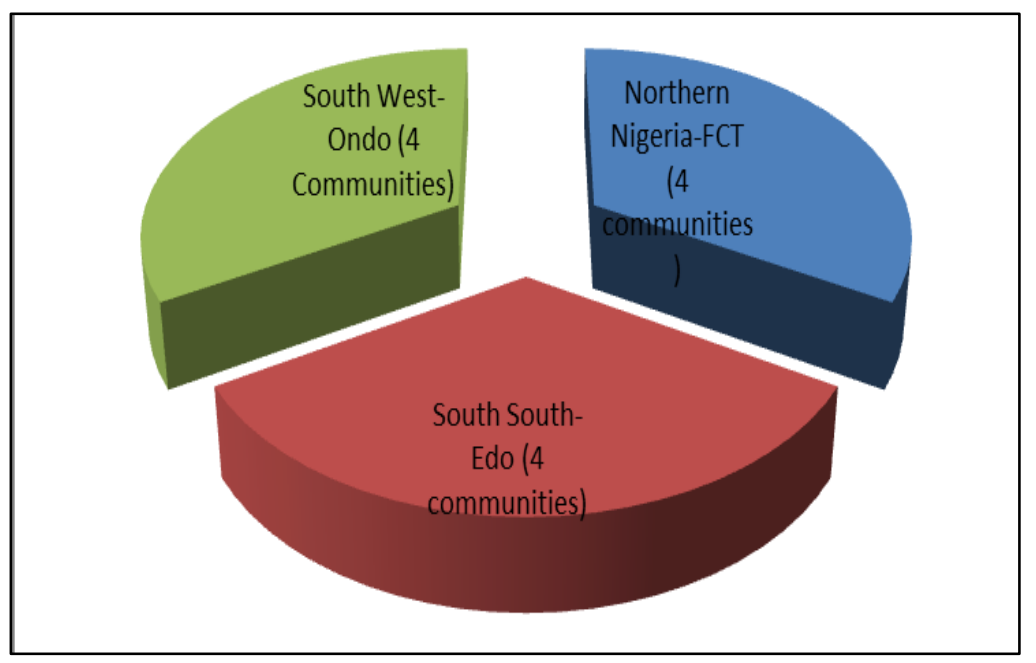

Figure 1. Study Locations

\subsection{Questionnaire}

A self-administered, semi-structured questionnaire was used for the survey. There were a total of 31 questions and these were divided into three sections. The first section generated information on the socio-demographic data of the respondents; the second section assessed respondents' perception on the community structures for demand generation on youth friendly services and the third section assessed their perspective on the barriers limiting their access to the SRH services offered at the PHCs as well as their suggestions for better access to these services.

\subsection{Focal Group Discussion}

A total of 12 focus group discussions (FGD) were conducted among community youth to elicit information on the perceptions of youth friendly services and barriers that limit their access to the SRH services provided in the Primary Health Care (PHC) Centres within their various communities. The FGD guide was used because of the nature of the research, the need to develop themes and also because they provide opportunity for probing. The guide contained an introduction of the researcher and full disclosure of the research, ethical considerations as well as request for consent. This was followed by a 12- question guide on issues relating to their knowledge about the sexual and reproductive health problems of youth in the communities, accessibility of PHC centres, health workers' attitude, their opinion on the approaches to youth mobilization for increase in patronage of these PHC centres for youth friendly services and the mode of information transmission within their communities.

\subsection{Key Informant Interview}

A total of 42 Key Informant Interviews (KII) were conducted among community leaders, religious leaders, women leaders, youth leaders, parents and teachers in the selected communities to elicit information on their perceived barriers limiting youth access to the SRH services within the PHC centres in their various communities. The KII guide contained an introduction of the researcher and full disclosure of the research, ethical considerations as well as request for consent. This was followed by a 12-question guide on issues relating to their knowledge about the status of youth friendly services and their general opinion in terms of general sexual and reproductive health issues in relations to youth in the communities.

The information from the FGD and KII were transcribed and analyzed for themes and contents. Also, the questionnaires were coded for data entry. The research team ensured privacy during the interviews and in reporting of data.

\section{Results}

The age of respondents ranged from 11 to 25 years with a mean of $18.9 \pm 4.4$ years SD and a median of 18.0 years. Majority (54.9\%) of the respondents fell between the 16 and 20 age group. Majority (51.3\%) of the respondents was males and $73.3 \%$ were Christians. A large percentage (84.3\%) of the respondents was single while only $15.7 \%$ were married. The highest educational qualifications of respondents were: no formal education $(4.0 \%)$, primary (22.0\%), secondary (68.3\%) and tertiary (5.7\%). Majority (71.0\%) of the respondents were students while only $14.3 \%$ were self-employed. Sixty two percent of the respondents were in-school youth while $38.0 \%$ were out-of-youth 


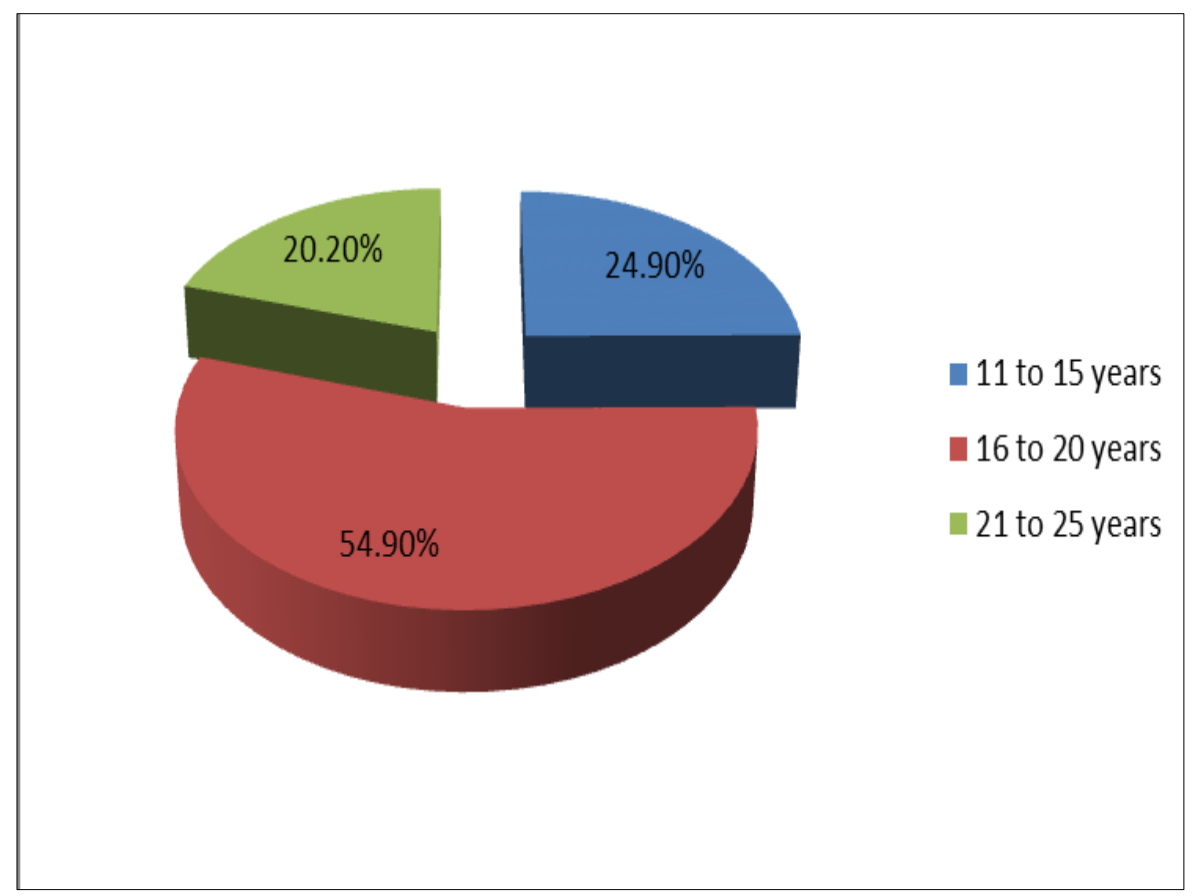

Figure 2. Age disaggregation of respondents

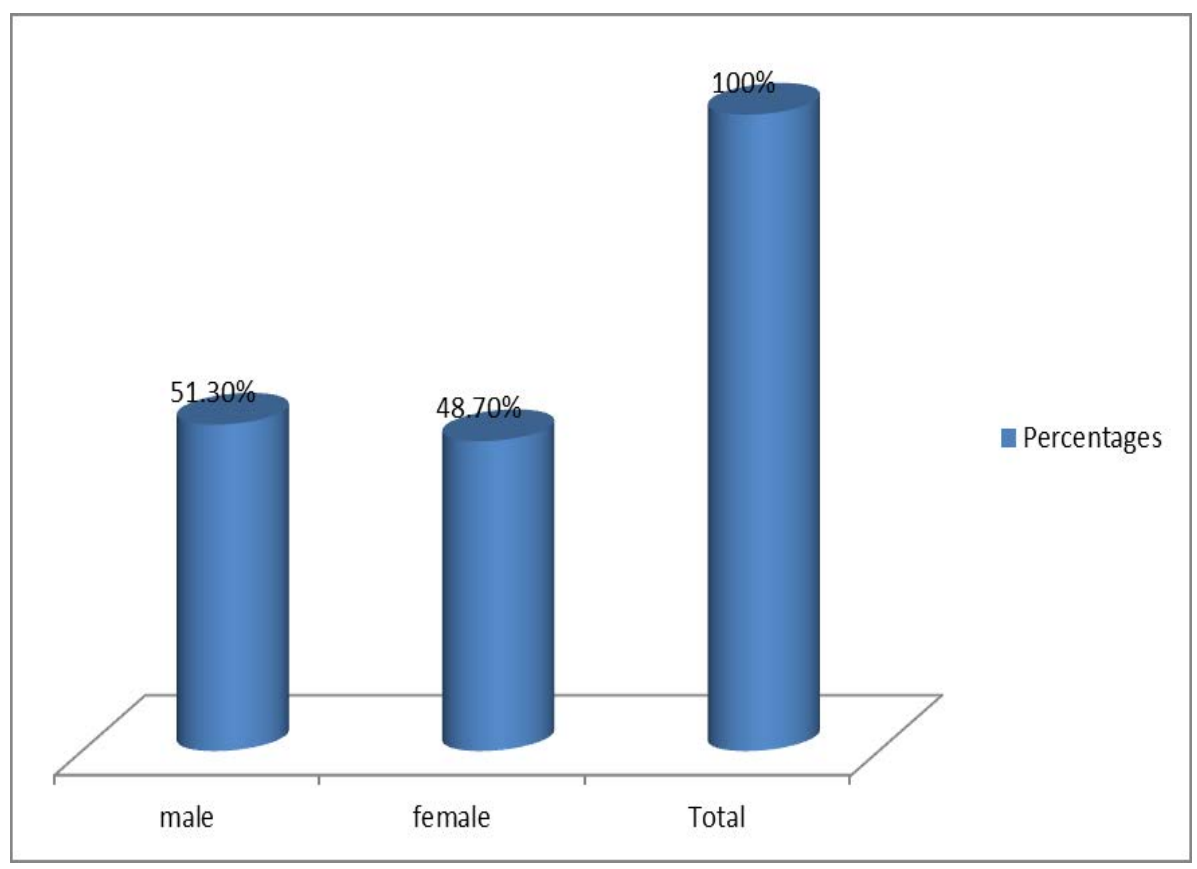

Figure 3. Gender disaggregation of respondents

A large percentage (80.0\%) of the respondents were of the opinion that youth counsellors are best at serving other youth in the community because they can relate to their health needs better while $25.6 \%$ of them believed that adult counsellors are more experienced and best at serving youth. Less than half (49.7\%) of the repondents agreed that youth do not need their parents' support to patronise SRH facilities in the community. Forty three percent (43\%) and
$74 \%$ of the respondents were of the view that they need the support of the religious leaders and community leaders respectively to increase youth participation in SRH activities and patronage to the PHC facilities in their community. Majority (81.7\%) of the respondents agreed that in-school clubs can create demand for SRH services and $64.7 \%$ of them also agreed that out-of-school clubs are important for SRH services. 


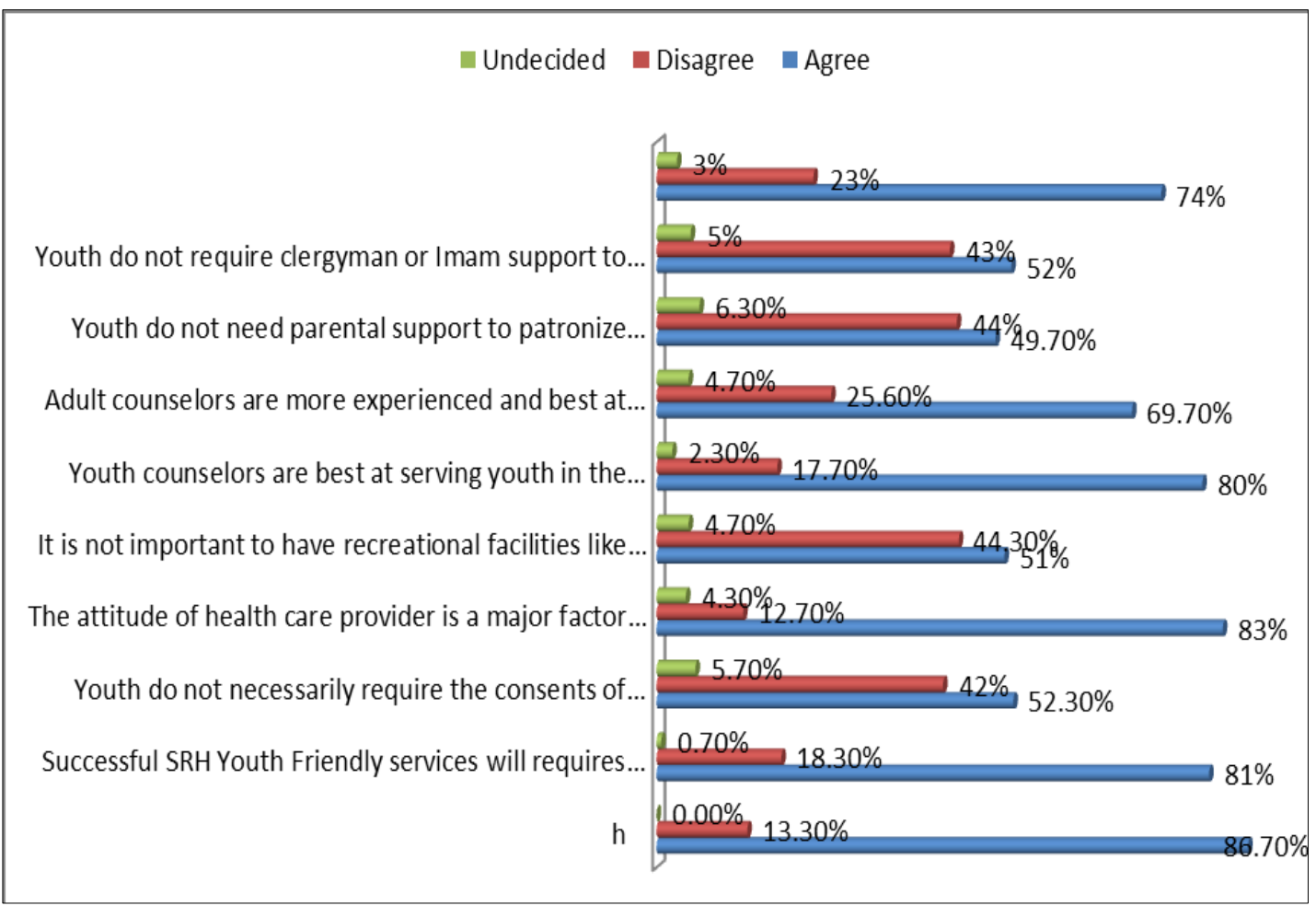

Figure 4. Respondents perceptions and demand creation for SRH services

\section{Barriers limiting youth's access to SRH services}

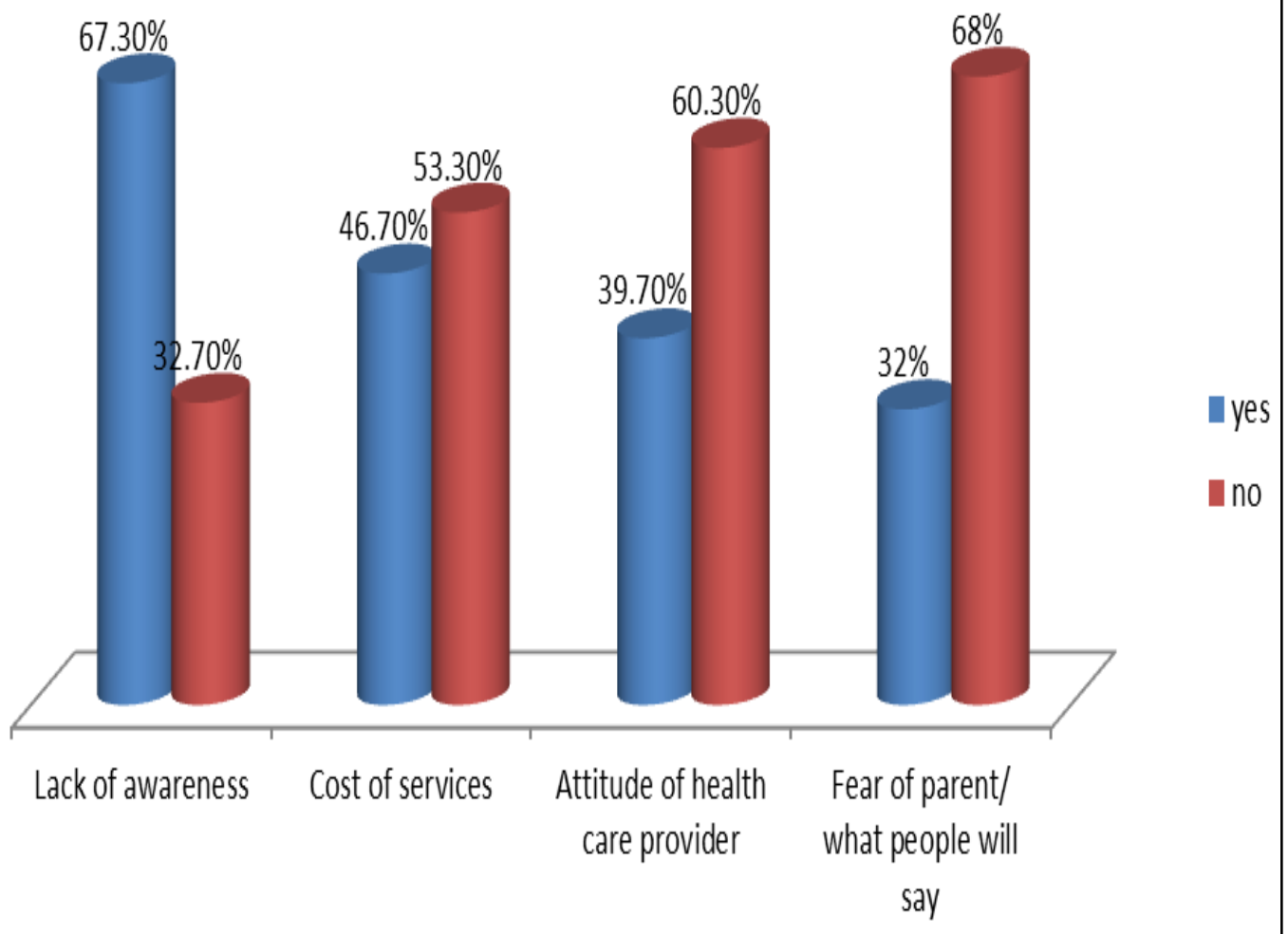

Figure 5. Barriers limiting youth's access to SRH services 


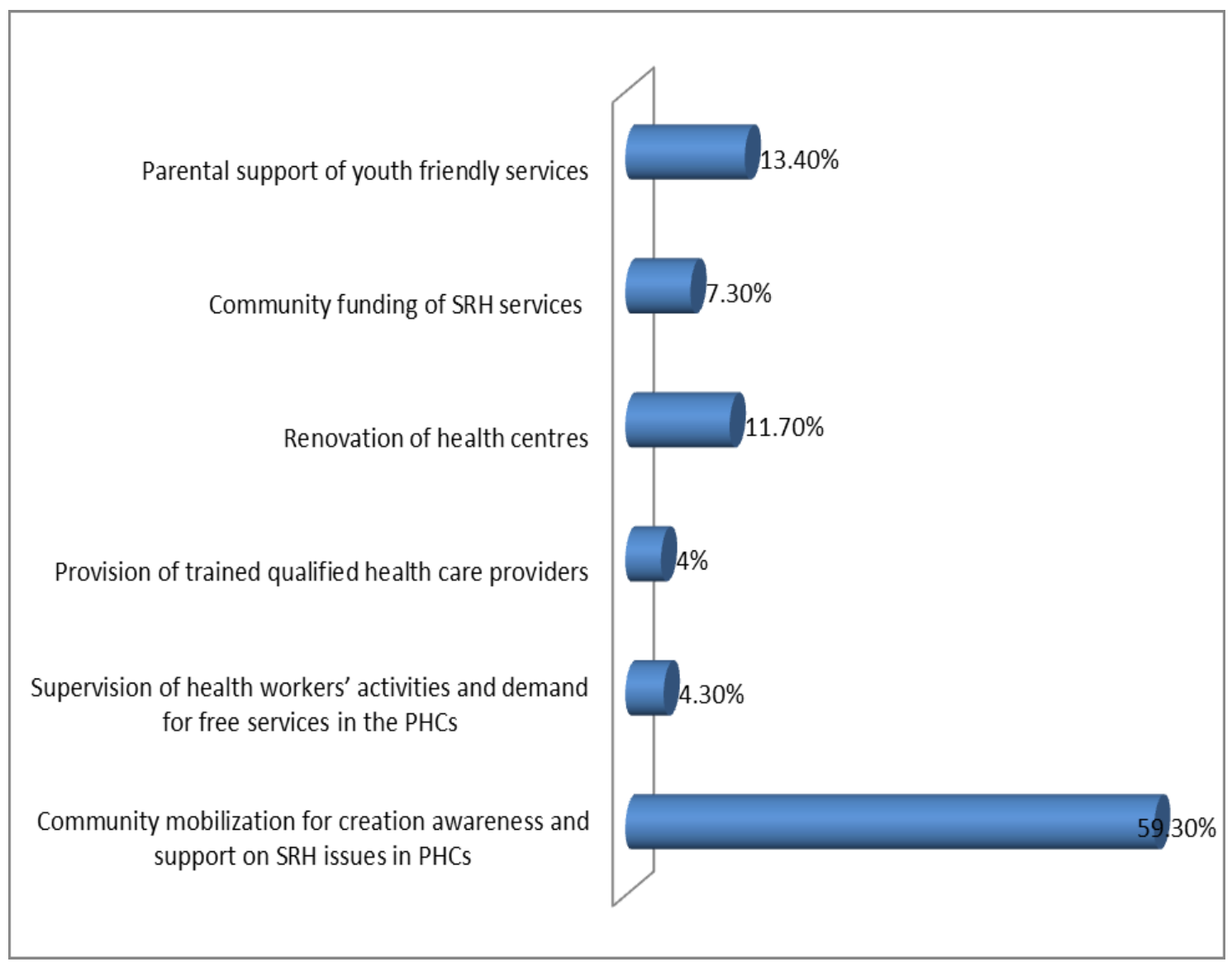

Figure 6. Suggested measures to create demand for ASRH services

Findings from the KII and focal group discussion were same as it showed that participants had poor knowledge about youth friendly services in the primary health care facilities; in fact most of the discussants were not aware of the availability of these services within PHC centres. However, some who had knowledge of its presence were not pleased with the placement of the health centres with reasons that it too far from their houses and that they are not well equipped for sexual and reproductive health services.

\section{Discussion}

Lack of awareness, inadequate information, attitude of health care providers and other significant barriers posed by the current state of most SRH services are perceived as unwelcoming to young clients. Given that the consequences of poor reproductive health in adolescence, such as those stemming from teenage pregnancy or acquiring STI have serious implications for the future as well as the present, there is need to find practical ways to assess the current operations of primary health facilities and take steps to ensure that they are "youth friendly" .

The demographic findings revealed that majority (54.9\%) of the respondents fell between the 16 and 20 age group. While a large percentage (84.3\%) of the respondents were single. The highest educational qualifications of respondents were secondary (68.3\%) while majority (71.0\%) was students. Sixty two percent $(62 \%)$ of the respondents were in-school youth while $38.0 \%$ were out-of-school-youth. Despite the obvious demographic shift in the country, the state of program delivery and research in the field of adolescent and youth health particularly with priority of primary level of care, is scarcely placed on the front burner. Many young people bear the burden of poor health owing to the effects of accidents and injuries including those caused by insecurity, war, poor sexual orientation and occupation. At the community level, youth are often compounded by cumulative toll of violence, unplanned pregnancy with resultant complications from unsafe and complicated abortions, HIV/AIDS and now tuberculosis on youth is adding to the already heavy price still being paid by child victims of malaria and poverty. 


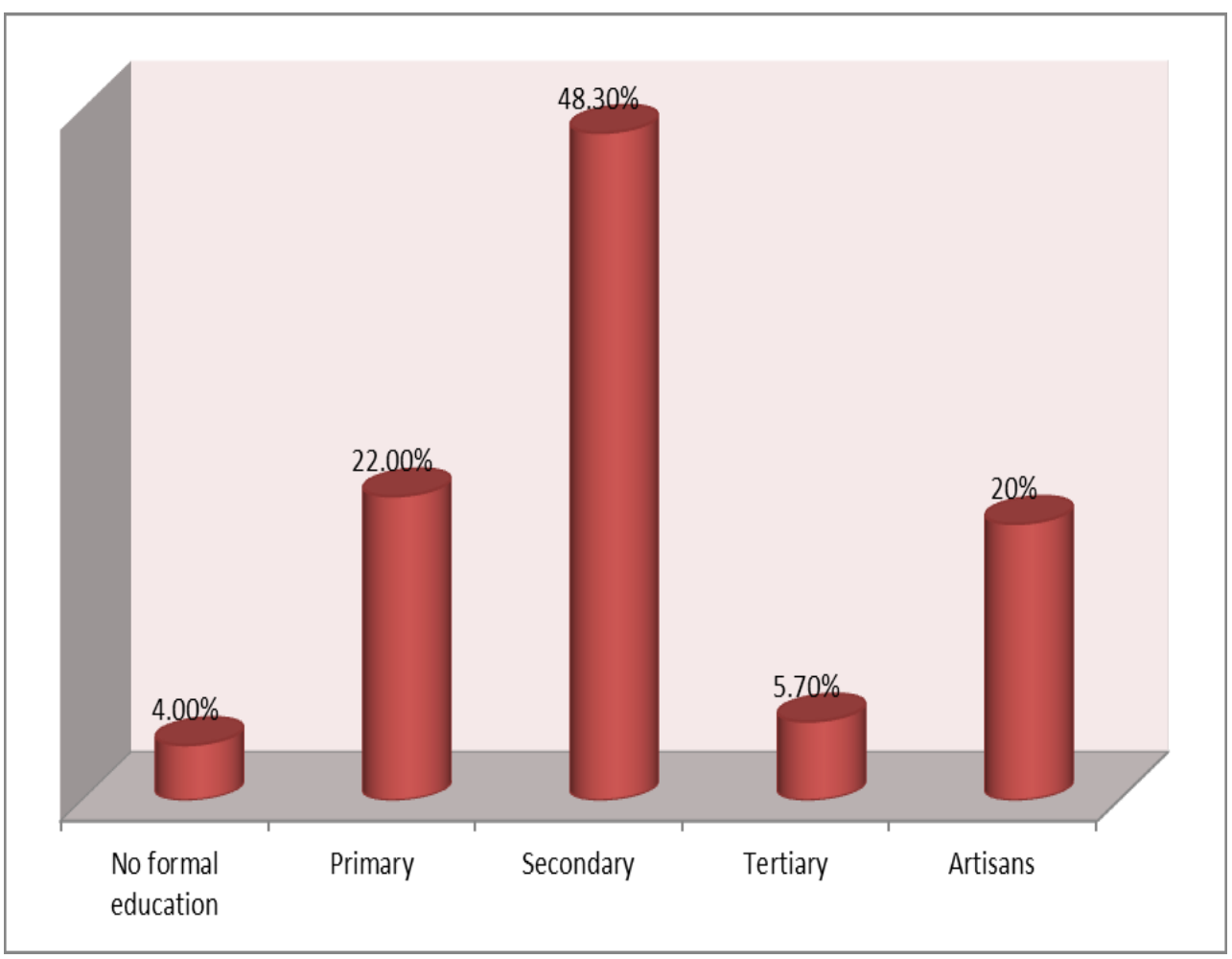

Figure 7. Level of education of respondents

Given that young people tend not to use existing reproductive health services, specialized approaches must be established to attract, serve, and retain young clients. From young people's points of view, they face many barriers to service use, including laws and policies that may restrict their access to affordable services and useful information, embarrassment at being seen at clinics, fear that confidentiality will not be honored, and concern that staff members will be hostile and judgmental ${ }^{10}$

Many operational barriers also exist, such as inconvenient operating times, lack of transportation, and high cost of services. Many of these barriers can be addressed by programs serving young people. In Nigeria efforts have been made over the years in both policy and programme fronts at improving the reproductive health status of Nigerian adolescents which has been described as very poor11. Perhaps the single most important action any reproductive health program for young adults can implement is the selection, training, and supervision of staff members to work with adolescents, with a major emphasis on attitude, respect for young people, and the development of interpersonal skills to promote good provider-client communication. Other provider characteristics that programs should consider include an emphasis on privacy and confidentiality, the allowance of adequate time for discussion, and the availability of trained peers as a counseling option 12

The assessment also provided information on the importance of involving young people in identifying problems. A large percentage (87.0\%) of the respondents were of the opinion that for SRH service to be holistic, schools must be involved in education of young persons on reproductive health. Majority (80.4\%) of them also opined that religious institutions must be involved in the education of youth on reproductive health issues developing solutions to ensure that program, policies and health services address their needs. The youth are the future of society, but they are also very much its present. Around half of the world's inhabitants are under the age of 20. Adolescents who are healthy and happy are better equipped to contribute to their communities as young citizens. Bad habits and poor hygiene, increased sexual vices, persistent behavioural risks, poor basic sanitation, and new and emerging diseases are contributing to a deadly mix that is changing the classic picture of healthy youth due to poor attention and care by the hitherto traditional institutions at the primary level of care.

\section{Conclusions}

From the findings, it is important to note that adolescence is a dynamic concept and young people are essential players in the community. The sexual and reproductive health needs of adolescents are severely underserved and the provision of youth-friendly services alone is not sufficient to meet them. However, the moderating influence of a safe and supportive environment and its contribution to sound mental health, the containment of violence and a sense of belonging can easily be lost for individual young people and the youth population cohorts as a whole when young persons are not 
rightly directed. Parents, teachers, religious leaders and health providers are agents of community education and directions for youths. They should be educated to understand, accept and respond to the specific situations of pubescent children, of early, middle and late adolescents, and of youth. Efforts therefore, should be made by all relevant stakeholders for the inclusion of Community-based facilitated education sessions, Youth centres, Information, Education, Communication (IEC) outreach from health facilities, Community participation and mobilization, Peer education and counselling, Life skills education or broader youth development approaches, Use of media, Voucher finance interventions, and Multi-component and multi-sectoral approaches as potential indicators for increasing youth access to SRH services in the PHC's.

\section{Acknowledgements}

The authors acknowledge the Ford Foundation for providing funding support for the study. Special thanks to the community stakeholders, adolescents, leadership of the LGAs and desk officers in Ondo, Edo and Federal Capital Territory, the National Primary Health Care Development Agency (NPHCDA) and the Federal Ministry of Health (FMOH) for their support in this exercise.

\section{REFERENCES}

[1] Nigeria Demographic and Health Survey pp 12, 2008

[2] A. Odaga. Youth and HIV/AIDS in Africa: A Call for Effective Policies and Programs Editorial, African Journal of Reproductive Health, 16(2):17 June 2012

[3] State of world population 2005: the promise of equality, United Nations Populations Fund, New York (2005). https://www.unfpa.org/publications/state-world-population2005

[4] M. Ezzati, A. D. Lopez, A .Rodgers, S. Vander Hoorn, C. J. L. Murray. The Comparative Risk Assessment Collaborating Group. Selected major risk factors and global and regional burden of disease. Lancet 360: 1347-1360. 2002;

[5] R. M. Mbeba, M. S. Mkuye, G. E. Magembe, W. L. Yotham, A. O. Mellah, S. B. Mkuwa. Barriers to sexual reproductive health services and rights among young people in Mtwara district, Tanzania: a qualitative study Pan African Medical Journal. 2012.

[6] The Safe Project Good practice in sexual and reproductive health and rights for young people: Comprehensive youth-friendly services youth-friendly services. www.ysafe.net. 2007

[7] E. L. Ahanonu, Attitudes of Healthcare Providers towards Providing Contraceptives for Unmarried Adolescents in
Ibadan, Nigeria. Journal of Family Reproductive Health. Mar; 8(1):33-40ps://www.ncbi.nlm.nih.gov/pubmed/24971 131. 2014

[8] Marie Stopes International. Delivering sexual and reproductive health services to young people: https://mariestopes.org/media/2117/delivering-sexual-and-r eproductive-health-services-to-young-people.pdf

[9] J. Senderowit, G. Hainsworth, C. A Solter. Rapid Assessment of Youth Friendly Reproductive Health Services Pathfinder International Number 4. http://www.pathfinder.org/publications. 2003

[10] S. B. Agampodi, T. C. Agampodi, P. Ukd. Adolescents perception of reproductive health care services in Sri Lanka. .BMC Health Service Research..; 8:98. May 32008

[11] Federal Ministry of Health [Nigeria] National policy on the health and development of adolescents and young people in Nigeria; Abuja: 2007.

[12] FOCUS on Young Adults (FYA), Making Reproductive Health Services Youth Friendly 1201 Connecticut Avenue NW, Suite 501 Washington DC 20036 202-835-0818. 1999 